\title{
EXTRATO AQUOSO DE RAMOS DE Trichilia pallida E O DESENVOLVIMENTO DE Spodoptera frugiperda EM GENÓTIPOS DE MILHO
}

\author{
Sônia Martins Torrecillas ${ }^{1}$; José Djair Vendramim \\ ${ }^{1}$ IAPAR, C.P. 481 - CEP: 86001-970 - Londrina, PR. \\ ${ }^{2}$ Depto. de Entomologia, Fitopatologia e Zoologia Agrícola - USP/ESALQ, C.P. 9 - CEP: 13418-900 - Piracicaba, SP. \\ *Autor correspondente <jdvendra@carpa.ciagri.usp.br>
}

\begin{abstract}
RESUMO: Avaliaram-se o desenvolvimento e a sobrevivência da lagarta-do-cartucho, Spodoptera frugiperda (J. E. Smith) criada em folhas de dois genótipos de milho (o padrão comercial C 901 e o resistente CMS 23) tratados com extratos aquosos (0,1 e 1\%) de ramos da planta inseticida Trichilia pallida Swartz (Meliaceae). As variáveis biológicas avaliadas foram peso, duração e viabilidade das fases larval e pupal. Em plantas tratadas com o extrato a $1 \%$, ocorreu mortalidade total das lagartas nos dois genótipos, enquanto que a $0,1 \%$ o extrato reduziu a sobrevivência e o peso larval e prolongou o período de desenvolvimento. Lagartas alimentadas com o genótipo CMS 23 apresentaram menor sobrevivência, menor peso e maior período de desenvolvimento do que no genótipo C 901.

Palavras-chave: Trichilia pallida, lagarta-do-cartucho, milho, planta inseticida, resistência de plantas
\end{abstract}

\section{AQUEOUS EXTRACT OF Trichilia pallida AND THE DEVELOPMENT OF Spodoptera frugiperda ON CORN GENOTYPES}

\begin{abstract}
The effect of aqueous extract of Trichilia pallida Swartz (Meliaceae) twigs was evaluated in relation to the development and survival of Spodoptera frugiperda (J. E. Smith) reared on two corn genotypes, the commercial standard C 901 and the resistant variety CMS 23. Newly hatched larvae of $S$. frugiperda were fed on the corn genotypes previously treated with the extract at concentrations of 0.1 and $1 \%$. The following parameters were evaluated: weight, duration and viability of the larval and pupal stages. All larvae died when the $1 \%$ extract was used on both corn genotypes. At the concentration of $0.1 \%$, the extract reduced the larval survival and weight, and prolonged the development period. Survival, weight and development period of the larvae were also affected by the genotype CMS 23.

Key words: Trichilia pallida, fall armyworm, corn, botanical insecticide, plant resistance
\end{abstract}

\section{INTRODUÇÃO}

A lagarta-do-cartucho, Spodoptera frugiperda (J. E. Smith), destaca-se como importante praga do milho, tanto pela redução da produtividade e da qualidade do produto final, quanto pela dificuldade de controle (Carvalho, 1982; Waquil et al., 1982; Bianco, 1991). Dentre as opções para o estabelecimento de uma estratégia adequada de manejo dessa praga, pode-se destacar a utilização de variedades resistentes a insetos que apresenta uma série de vantagens, dentre as quais a compatibilidade com outras técnicas de controle. Genótipos de milho resistentes à lagarta-do-cartucho têm sido relatados em diversos trabalhos de pesquisa ( Lara et al., 1984; $\mathrm{Ng}$ et al., 1985; Melo \& Silva, 1987; Vendramim \& Fancelli, 1988; Williams \& Buckley, 1992; Silveira et al., 1997). Uma extensa revisão do assunto foi feita por Silveira (1994).

Ainda que a utilização exclusiva de genótipos resistentes não proporcione um controle satisfatório das pragas, o emprego de variedades com níveis baixos ou moderados de resistência pode ser vantajoso, caso sua potencialidade possa ser incrementada com a associação de outros fatores. Por outro lado, o emprego de inseticidas botânicos é uma técnica de controle que tem conquistado espaço nos últimos anos, principalmente em função dos resultados promissores obtidos com os extratos de Azadirachta indica A. Juss. (Meliaceae) em relação a inúmeros insetos pragas incluindo S. frugiperda (Mikolajczak \& Reed, 1987; Mikolajczak et al., 1989; Breuer \& Devkota, 1990; Maredia et al., 1992; Mordue (Luntz) \& Blackwell, 1993), os quais apresentam ainda a vantagem de ser pouco tóxicos para animais de sangue quente (Koul et al., 1990).

Nos últimos anos, inúmeras plantas com atividade inseticida, pertencentes a diversas famílias botânicas, têm sido descobertas, encontrando-se listagens destas na literatura internacional (Grainge \& Ahmed, 1988). Pesquisas recentes revelaram a existência de outras espécies promissoras, destacando-se, entre estas, Trichilia pallida Swartz (Meliaceae), cujos ramos apresentam atividade inseticida contra a lagarta-do-cartucho (Rodríguez \& Vendramim, 1996; Roel \& Vendramim, 1999). Esta árvore vulgarmente conhecida como baga-demorcego ou catiguá é amplamente distribuída do México à Argentina e, no Brasil, pode ser encontrada em bosques nativos desde a Amazônia até o Paraná, excetuando-se o Nordeste (Klein, 1984; Soares-Silva \& Barroso, 1992). 
A utilização de resistência varietal associada a plantas inseticidas pode se constituir numa alternativa viável para o controle de pragas, principalmente considerando-se que os sistemas de produção auto-sustentáveis requerem a implantação de metodologias menos agressivas e que possam ser mantidas por um maior período de tempo como parte do agroecossistema. Assim, esta pesquisa teve por objetivo avaliar o desenvolvimento e a sobrevivência de $S$. frugiperda em genótipos resistente e suscetível de milho tratados com extratos aquosos de ramos de T. pallida.

\section{MATERIAL E MÉTODOS}

Os genótipos de milho utilizados foram o CMS 23, tido como resistente a S. frugiperda (Viana et al., 1992; Guimarães \& Viana, 1994), e o padrão comercial C 901. Os ramos (galhos sem folhas) de T. pallida foram coletados no Bosque Municipal de Pedreira, SP e, após secagem (em estufa a $40^{\circ} \mathrm{C}$, durante quatro dias), foram moídos até a obtenção de pó fino. Os extratos aquosos foram obtidos misturando-se o pó em água destilada na concentração de $1 \%$ (peso/volume), agitando-se em liqüidificador até a completa homogeneização. A mistura foi então mantida em recipientes de vidro com tampa por $24 \mathrm{~h}$ para completar o processo de extração. No momento da utilização, a mistura foi filtrada, através de tecido fino ("voil"), obtendo-se uma suspensão homogênea, parte da qual foi diluída à concentração de $0,1 \%$ (volume/volume). O tratamento dos genótipos de milho com os extratos foi feito mergulhandose, por dois segundos, pedaços de folhas (com cerca de $4 \times 7 \mathrm{~cm}$ ) nas suspensões a 1 ou $0,1 \%$. Folhas de cada genótipo mergulhadas em água destilada foram utilizadas como testemunhas. A seguir, os pedaços de folhas foram mantidos ao ar livre até a evaporação do excesso de água.

Para observação do desenvolvimento de $S$. frugiperda, foram utilizados tubos de vidro $(8,5 \times 2,5 \mathrm{~cm})$ contendo os pedaços de folhas, onde lagartas recémeclodidas foram individualmente confinadas, tamponandose os tubos com algodão hidrófugo. Os frascos foram mantidos em prateleiras, em laboratório, a $23 \pm 2^{\circ} \mathrm{C}$, UR de $70 \pm 10 \%$ e fotofase de $14 \mathrm{~h}$. As folhas foram substituídas diariamente por outras folhas tratadas, anotando-se 0 número de lagartas mortas. Isto foi feito até o estádio de pré-pupa (considerado como parte da fase larval), ocasião em que o alimento foi suprimido. As lagartas sobreviventes foram pesadas aos 10 e 15 dias de idade. As pupas, pesadas 24 horas após a formação, foram mantidas nos tubos de vidro até a emergência de adultos. As variáveis biológicas avaliadas foram peso, duração e viabilidade das fases larval e pupal.

O delineamento estatístico foi inteiramente casualizado, com seis tratamentos, envolvendo dois genótipos e três concentrações $(0 ; 0,1$ e $1 \%)$ do extrato, e quatro repetições (grupos de 10 lagartas cada), totalizando 40 indivíduos por tratamento. A análise de variância seguiu o esquema fatorial, considerando-se os genótipos e o extrato como fatores, sendo as médias comparadas pelo teste de Tukey $(P \leq 0,05)$.

\section{RESULTADOS E DISCUSSÃO}

O extrato de ramos de $T$. pallida à concentração de $1 \%$ apresentou forte atividade inseticida, matando todas as lagartas de $S$. frugiperda antes que elas atingissem 10 dias de idade. Em função disso, a única variável avaliada para esse tratamento foi a viabilidade larval.

Os dados de peso larval aos 10 e 15 dias evidenciam que tanto 0 fator genótipo quanto 0 fator extrato reduziram a taxa de desenvolvimento de $S$. frugiperda, sendo também significativa a interação destes fatores (TABELA 1). Essa interação fica caracterizada ao se observar que tanto aos 10 , como aos 15 dias, a redução de peso causada pelo genótipo só foi constatada nas parcelas sem utilização do extrato. Os insetos desenvolvidos no material resistente CMS 23, sem aplicação de extrato de T. pallida, apresentaram peso menor que os desenvolvidos no padrão C 901. Com o uso do extrato, os pesos médios das lagartas foram bastante baixos, não tendo sido constatada diferença entre os genótipos, possivelmente em razão da pronunciada atividade deletéria do extrato, que pode ter mascarado o efeito do material resistente. A redução significativa de peso larval causada pelo extrato, por outro lado, foi constatada nos dois genótipos.

A similaridade dos resultados com lagartas de 10 e 15 dias indica que o inseto, na necessidade de degradar possíveis aleloquímicos presentes no genótipo resistente e no extrato, pode ter desviado para esta finalidade recursos que seriam utilizados para ganho de biomassa (Tanzubil \& McCaffery, 1990).

A viabilidade larval também foi afetada pelos dois fatores, sendo ainda significativa a interação desses fatores (TABELA 2). Conforme relatado anteriormente, com o extrato a $1 \%$, a viabilidade foi nula nos dois genótipos. Embora o material resistente tenha causado redução da viabilidade tanto nas parcelas tratadas como nas testemunhas, essa redução foi mais acentuada na presença do extrato a $0,1 \%$, (de 48,8 para $15,9 \%$ ) que na ausência dele (de 100 para $85,7 \%$ ). A redução da viabilidade devido ao extrato, por outro lado, foi constatada nos dois genótipos, havendo, também neste caso, variação na intensidade do referido efeito com maior redução no genótipo CMS 23 (de 85,7 para 15,9\%) que em 'C 901' (de 100 para 48,8\%) (TABELA 2).

Tanto o genótipo resistente como o extrato afetaram a duração da fase larval dos insetos sobreviventes, mas, nesse caso, o efeito da interação desses fatores não foi significativo (TABELA 3). Considerando-se a média da duração da fase larval (entre insetos desenvolvidos em parcelas tratadas e não tratadas), verifica-se um prolongamento de cerca de 2 dias em 'CMS 23 ' em relação a 'C901'. Analisando-se o efeito do extrato, verifica-se que, em média para os dois genótipos, ocorreu um prolongamento ainda maior (mais de 5 dias) quando são comparados os tratamentos com e sem extrato. $O$ atraso no desenvolvimento larval pode ser conseqüência da inadequação nutricional do 
TABELA 1 - Peso de lagartas de Spodoptera frugiperda, aos 10 e 15 dias, alimentadas com genótipos de milho tratados com extratos aquosos de ramos de Trichilia pallida.

\begin{tabular}{|c|c|c|c|c|}
\hline \multirow[t]{2}{*}{ Genótipo } & \multicolumn{2}{|c|}{10 dias $(\mathrm{cv}=28,76 \%)$} & \multicolumn{2}{|c|}{15 dias $(\mathrm{cv}=24,10 \%)$} \\
\hline & Testemunha & Extrato $(0,1 \%)$ & Testemunha & Extrato $(0,1 \%)$ \\
\hline & - & 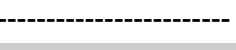 & -----. & י-ני-ני \\
\hline C 901 & $26,4 \mathrm{Aa}^{1}$ & $5,0 \mathrm{Ba}$ & $205,7 \mathrm{Aa}$ & $34,9 \mathrm{Ba}$ \\
\hline CMS 23 & $9,0 \mathrm{Ab}$ & 2,8 Ba & $81,1 \mathrm{Ab}$ & $16,9 \mathrm{Ba}$ \\
\hline
\end{tabular}

${ }^{1}$ Médias seguidas da mesma letra maiúscula, na horizontal, e minúscula, na vertical, não diferem pelo teste de Tukey $(P \leq 0,05)$.

TABELA 2 - Viabilidade da fase larval de Spodoptera frugiperda alimentada com genótipos de milho tratados com extratos aquosos de caules de Trichilia pallida.

\begin{tabular}{lccc}
\hline Ge nótipo & Testemunha $^{1}$ & $\begin{array}{c}\text { Extrato } \\
(0,1 \%)^{1}\end{array}$ & $\begin{array}{c}\text { Extrato } \\
(1 \%)^{2}\end{array}$ \\
\hline C 901 & $100,0 \mathrm{Aa}$ & $48,8 \mathrm{Ba}$ & 0,0 \\
CMS 23 & $85,7 \mathrm{Ab}$ & $15,9 \mathrm{Bb}$ & 0,0 \\
\hline
\end{tabular}

$\mathrm{CV}=19,93 \%$

${ }^{1}$ Médias seguidas da mesma letra maiúscula, na horizontal, e minúscula, na vertical, não diferem pelo teste de Tukey $(P \leq 0,05)$.

²Dados não incluídos na análise (variância nula).

TABELA 3 - Duração da fase larval de Spodoptera frugiperda alimentada com genótipos de milho tratados com extratos aquosos de ramos de Trichilia pallida.

\begin{tabular}{lccc}
\hline Genótipo & Testemunha & Extrato $(0,1 \%)$ & Média \\
\hline C 901 & ---------- \\
CMS 23 & 23,7 & 29,7 & $26,7 \mathrm{~b}^{1}$ \\
\hline Média & 26,1 & 31,0 & 28,5 a \\
\hline
\end{tabular}

$\mathrm{CV}=5,63 \%$

${ }^{1}$ Médias seguidas da mesma letra maiúscula, na horizontal, e minúscula, na vertical, não diferem pelo teste de Tukey $(P \leq 0,05)$.

substrato alimentar (Rodríguez \& Vendramim, 1996) ou da menor eficiência de conversão do alimento ingerido e digerido, resultado do desvio de parte da energia para a degradação de substâncias tóxicas presentes no referido substrato (Tanzubil \& McCaffery, 1990).

Embora tenha ocorrido alguma variação no peso e na viabilidade pupal, as diferenças foram mínimas e não houve diferença significativa entre as médias dessas variáveis (TABELAS 4 e 5). O prolongamento da fase larval sem a correspondente redução no peso de pupas nas parcelas tratadas possivelmente se deva à presença de doses baixas de substâncias tóxicas na concentração de
TABELA 4 - Peso de pupas de Spodoptera frugiperda provenientes de lagartas alimentadas com genótipos de milho tratados com extratos aquosos de ramos de Trichilia pallida.

\begin{tabular}{|c|c|c|c|}
\hline Genótipo & Testemunha & Extrato $(0,1 \%)$ & Média \\
\hline & \multicolumn{3}{|c|}{-------------------- mg --------------------- } \\
\hline C 901 & 217,8 & 193,3 & $205,6 a^{1}$ \\
\hline CMS 23 & 202,9 & 185,4 & 194,2 a \\
\hline Média & $210,3 \mathrm{~A}$ & $189,4 \mathrm{~A}$ & \\
\hline
\end{tabular}

$\mathrm{CV}=10,54 \%$

${ }^{1}$ Médias seguidas da mesma letra maiúscula, na horizontal, e minúscula, na vertical, não diferem pelo teste de Tukey $(P \leq 0,05)$.

TABELA 5 - Viabilidade da fase pupal de Spodoptera frugiperda proveniente de lagartas alimenta das com genótipos de milho tratados com extratos aquosos deramos deTrichilia pallida.

\begin{tabular}{lccc}
\hline Genótipo & Testemunha & Extrato $(0,1 \%)$ & Média \\
\hline C 901 & --------------- & $\%$ \\
& 96,4 & 93,8 & $95,1 \mathrm{a}^{1}$ \\
CMS 23 & 87,5 & 66,7 & $77,1 \mathrm{a}$ \\
\hline Média & $92,0 \mathrm{~A}$ & $80,2 \mathrm{~A}$ & \\
\hline
\end{tabular}

$\mathrm{CV}=30,09 \%$

${ }^{1}$ Médias seguidas da mesma letra maiúscula, na horizontal, e minúscula, na vertical, não diferem pelo teste de Tukey $(P \leq 0,05)$.

$0,1 \%$ do extrato. Segundo Tanzubil \& McCaffery (1990), estas doses baixas podem provocar inibição do crescimento, mas não da alimentação do inseto.

Em relação à duração da fase pupal, houve efeito significativo da interação dos fatores extrato e genótipo. O valor obtido para as pupas provenientes de lagartas alimentadas em folhas de 'CMS 23 ' tratadas com extrato foi menor que aqueles obtidos nos tratamentos 'CMS 23' sem extrato e 'C 901' com e sem extrato (TABELA 6). Esta redução na duração da fase pupal no tratamento em que tinha ocorrido a pior performance do inseto na fase larval, o que, em princípio, não era esperado, possivelmente se 
TABELA 6 - Duração da fase pupal de Spodoptera frugiperda provenientes de lagartas alimentadas com genótipos de milho tratados com extratos aquosos de ramos de Trichilia pallida.

\begin{tabular}{lcc}
\hline Genótipo & Testemunha & Extrato $(0,1 \%)$ \\
\hline & $10,4 \mathrm{Aa}^{1}$ & $11,0 \mathrm{Aa}$ \\
C 901 & $10,8 \mathrm{Aa}$ & $9,5 \mathrm{Bb}$ \\
CMS 23 & &
\end{tabular}

$\mathrm{CV}=5,63 \%$

${ }^{1}$ Médias seguidas da mesma letra maiúscula, na horizontal, e minúscula, na vertical, não diferem pelo teste de Tukey $(P \leq 0,05)$.

${ }^{2}$ Não houve sobrevivência larval na concentração de $1 \%$.

deva ao fato de ter ocorrido nesse tratamento uma seleção da população (em função da baixa viabilidade larval), permitindo a sobrevivência dos indivíduos mais vigorosos e, portanto, aptos a atingir mais rapidamente a fase adulta do que nos outros tratamentos.

As alterações no desenvolvimento de $S$. frugiperda ocorreram apenas na fase larval, indicando ser esta mais adequada que a pupal para avaliação do efeito dos referidos fatores. Resultados semelhantes foram obtidos por Vendramim \& Scampini (1997) que estudaram o efeito de dois genótipos de milho e do extrato aquoso de Melia azedarach sobre o referido inseto. Isto pode ser explicado pelo fato de ser essa a fase em que o inseto se alimenta, o que o torna mais exposto aos possíveis aleloquímicos presentes no genótipo resistente e na planta inseticida.

O fato de o genótipo CMS 23 ter reduzido a sobrevivência e o peso larval e prolongado a duração dessa fase sugere que, além da resistência por tolerância referida por Viana et al. (1992), este material também apresenta resistência por não-preferência para alimentação e/ou antibiose. Esta hipótese é reforçada principalmente pelos dados de viabilidade larval onde o efeito do extrato a $0,1 \%$, neste genótipo, foi mais drástico que no padrão C 901. A análise dessa variável indica também que os efeitos deletérios sobre 0 inseto foram mais acentuados quando o genótipo resistente e o extrato foram utilizados de forma associada que quando empregados de forma independente, sugerindo a ocorrência de sinergismo, ou seja, as lagartas desenvolvidas no genótipo resistente possivelmente teriam se tornado mais vulneráveis à ação de substâncias deletérias presentes no extrato de T. pallida. Vendramim \& Scampini (1997) encontraram resultados semelhantes com essa praga criada em genótipos resistente e suscetível de milho tratados com extrato de $M$. azedarach.

\section{REFERÊNCIAS BIBLIOGRÁFICAS}

BIANCO, R. Pragas e seu controle. In: FUNDAÇÃO INSTITUTO AGRONÔMICO DO PARANÁ. A cultura do milho no Paraná. Londrina: IAPAR, 1991. p.184-221. (Circular Técnica, 68).

BREUER, M.; DEVKOTA, B. Control of Thaumetopea pityocampa (Den. \& Schiff.) by extracts of Melia azedarach L. (Meliaceae). Journal of Economic Entomology, v.65, p.385-386, 1990.

CARVALHO, A.O.R. Pragas de milho e seu controle. Londrina: IAPAR, 1982. 291p. (Circular Técnica, 29).
GUIMARÃES, P.E.O.; VIANA, P.A. Sintético CMS 23 para a lagarta-do-cartucho, Spodoptera frugiperda. In: EMPRESA BRASILEIRA DE PESQUISA AGROPECUÁRIA. Centro Nacional de Pesquisa de Milho e Sorgo. Relatório Técnico Anual: 1992-1993. Sete Lagoas: EMBRAPA, CNPMS, 1994. p.136.

GRAINGE, M.; AHMED, S. Handbook of plants with pestcontrol properties. New York: John Wiley, 1988. 470p.

KLEIN, R.M. Meliáceas. In: REITZ, R. (Ed.) Flora ilustrada catarinense: Parte I. As plantas meliáceas. Itajaí: IBDF, 1984. p.40-46.

KOUL, O.; ISMAN, M.B.; KETKAR, C.M. Properties and uses of neem, Azadirachta indica. Canadian Journal of Botany, v.68, p.1-11, 1990.

LARA, F.M.; AYALA-OSUÑA, J.; ABDELNUR JR., O. Comportamento de genótipos de milho em relação ao ataque de Spodoptera frugiperda (J. E. Smith, 1797) e Heliothis zea (Bod., 1850). Científica, v.12, p.77-83, 1984.

MAREDIA, K.M.; SEGURA, O.L.; MIHM, J.A. Effects of neem, Azadirachta indica on six species of maize insect pests. Tropical Pest Management, v.38, p.190-195, 1992.

MELO, M.; SILVA, R.F.P. da. Influência de três cultivares de milho no desenvolvimento de Spodoptera frugiperda (J.E. Smith, 1797) (Lepidoptera: Noctuidae). Anais da Sociedade Entomológica do Brasil, v.16, p.37-49, 1987.

MIKOLAJCZAK, K.L.; REED, D.K. Extractivess of seeds of the Meliaceae: effects on Spodoptera frugiperda (J.E. Smith), Acalyma vittatum (F.), and Artemia salina Leach. Journal of Chemical Ecology, v.13, p.99-111, 1987.

MIKOLAJCZAK, K.L.; ZILKOWSKI, B.W.; BARTELT, R.J. Effect of meliaceous seed extracts on growth and survival of Spodoptera frugiperda (J. E. Smith). Journal of Chemical Ecology, v.15, p.121-128, 1989.

MORDUE (LUNTZ), A.J.; BLACKWELL, A. Azadirachtin: an update. Journal of Insect Physiology, v.39, p.903-924, 1993.

NG, S.S.; DAVIS, F.M.; WILLIAMS, W.P. Survival, growth, and reproduction of the fall armyworm (Lepidoptera: Noctuidae) as affected by resistant corn genotypes. Journal of Economic Entomology, v.78, 967-971, 1985

RODRÍGUEZ H., C.; VENDRAMIM, J.D. Toxicidad de extractos acuosos de Meliaceae en Spodoptera frugiperda (Lepidoptera: Noctuidae). Manejo Integrado de Plagas, v.42, p.14-22, 1996.

ROEL, A.R.; VENDRAMIM, J.D. Desenvolvimento de Spodoptera frugiperda (J. E. Smith) em genótipos de milho tratados com extrato acetato de etila de Trichilia pallida (Swartz). Scientia Agricola, v.56, p.581-586, 1999.

SILVEIRA, L.C.P. Resistência de genótipos de milho a Spodoptera frugiperda (J.E. Smith, 1797) (Lepidoptera: Noctuidae). Piracicaba, 1994. 90p. Dissertação (Mestrado) Escola Superior de Agricultura "Luiz de Queiroz", Universidade de São Paulo.

SILVEIRA, L.C.P.; VENDRAMIM, J.D.; ROSSETTO, C.J. Efeito de genótipos de milho no desenvolvimento de Spodoptera frugiperda (J.E. Smith). Anais da Sociedade Entomológica do Brasil, v.26, p.291-298, 1997.

SOARES-SILVA, L.H.; BARROSO, G.M. Fitossociologia do estrato arbóreo da floresta na porção norte do parque Estadual Mata dos Godoy, Londrina- PR, Brasil. In: CONGRESSO DA SOCIEDADE BRASILEIRA PARA O PROGRESSO DA CIÊNCIA, 8., Ouro Preto, 1992. Anais. São Paulo: SBPC, 1992. p.101-112

TANZUBIL, P.B.; McCAFFERRY, A.R. Effects of azadirachtin and aqueous neem seed extracts on survival, growth and development of the african armyworm, Spodoptera exempta. Crop Protection, v.9, p.383-386, 1990. 
VENDRAMIM, J.D.; FANCELLI, M. Efeitos de genótipos de milho na biologia de Spodoptera frugiperda (J.E. Smith, 1797) (Lepidoptera:Noctuidae). Anais da Sociedade Entomológica do Brasil, v.17, p.141-150, 1988.

VENDRAMIM, J.D.; SCAMPINI, P.J. Efeito do extrato aquoso de Melia azedarach L. sobre o desenvolvimento de Spodoptera frugiperda (J.E. Smith) em dois genótipos de milho. Revista de Agricultura, v.72, p.158-170, 1997.

VIANA, P.A.; GUIMARÃES, P.E.; GOMES E GAMA, E.E.; SILVA, A.E. Melhoramento genético da população de milho CMS 23 para resistência à lagarta-do-cartucho, Spodoptera frugiperda. In: EMPRESA BRASILEIRA DE PESQUISA AGROPECUÁRIA. Centro Nacional de Pesquisa de Milho e Sorgo. Relatório Técnico Anual: 1988-1991. Sete Lagoas: EMBRAPA, CNPMS, 1992. p.95.
WAQUIL, J.E.; VIANA, P.A.; LORDELLO, A.I. Controle da lagartado-cartucho em milho com inseticidas químicos e biológicos. Pesquisa Agropecuária Brasileira, v.17, p.163-166, 1982.

WILLIAMS,W.P.; BUCKLEY, P. M. Growth of fall armyworm (Lepidoptera: Noctuidae) larvae on resistant and susceptible corn. Journal of Economic Entomology, v.85, p.2039-2042, 1992.

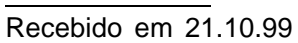

